\title{
DIRETORES DE TURMA NO ENSINO ARTICULADO DA MÚSICA: PERSPETIVAS E EXPERIÊNCIAS ${ }^{1}$
}

\section{Fernanda Martins ${ }^{2}$; Teresa Sarmento ${ }^{3}$}

\begin{abstract}
Resumo: A direção de turma constitui uma estrutura de gestão pedagógica intermédia, sendo desenvolvida por um professor designado entre o conjunto de professores de uma turma. Ao diretor de turma (DT) cabe um cargo de coordenação $e$ orientação educativas com uma tríplice função: orientação educativa dos alunos; relações com as famílias e coordenação dos restantes professores da turma. Embora a legislação atente para a identificação de perfis adequados na seleção de DTs, na prática o mesmo é entregue indiferenciadamente a qualquer professor da turma, independentemente do seu tempo de serviço, da sua experiência de liderança de grupos, da posse ou não de formação especializada, ou de outras variáveis. Atualmente, o DT tem no seu horário uma hora semanal na qual se prevê que dê resposta às múltiplas tarefas administrativas-burocráticas e de interação com alunos, pais $e$ professores.

O ensino articulado da música é uma componente do sistema educativo do ensino básico, de ordem opcional, que garante, aos alunos interessados, frequentar formação musical e instrumental, havendo, para isso, um sistema protocolarizado entre escolas do ensino regular e escolas especializadas de música. No âmbito do ensino especializado da música também está prevista a figura do DT com uma tripla função, no entanto, acresce o seu papel de representante dos professores de música no conselho de turma sedeado na escola do ensino regular, sob a direção do DT do ensino regular. Nestes casos, cabe aos dois DTs a articulação entre a escola de música e a escola do ensino regular.

$O$ presente artigo, o qual faz parte de um estudo mais alargado sobre a direção de turma (cf. Antunes, Gomes, Martins \& Sarmento,
\end{abstract}

\footnotetext{
${ }^{1}$ Este trabalho é financiado por Fundos Nacionais por meio da FCT - Fundação Para a Ciência e Tecnologia - no âmbito do projeto PEst-OE/CED/UI1661/2011 do CIEd (Portugal) e no âmbito do CIEC

2 Departamento de Ciências Sociais da Educação - Instituto de Educação Universidade do Minho. E-mail: fmartins@ ie.uminho.pt

3 Departamento de Ciências Sociais da Educação - Instituto de Educação Universidade do Minho. E-mail: tsarmento@ie.uminho.pt
} 
2012), baseia-se em dados empíricos de testemunhos de DTs de escolas de ensino especializado de música sobre as suas perspetivas e experiências como DT no ensino articulado da música, no que se refere à orientação educativa dos alunos, à relação com os pais/EE $e$ à coordenação docente com principal enfoque na coordenação entre o DT do ensino da música, o DT e os professores do ensino regular.

Palavras-chave: direção de turma; ensino articulado da música; coordenação docente; trabalho colaborativo.

\title{
CLASS DIRECTORS IN ARTICULATED MUSIC TEACHING: PERSPECTIVES AND EXPERIENCES
}

\begin{abstract}
In the Portuguese school system, form tutors (FT) are an intermediate education management structure. The form tutor is responsible for a position of coordination and orientation with a threefold function: relationship with students; relationship with the student's family and relationship with other class teachers. The joint teaching of music is a part of the educational system in basic education. It is optional and provides musical and instrumental training to students who are interested in taking it In order to achieve this, there is a system, subject to protocols, between general education schools and schools specializing in teaching music. There is also the position of FT in specialized schools and it also includes a threefold function, much like FTs in the previously mentioned teaching modality. However, these FTs have the additional role of representing music teachers at the class council which is held at the general education school. Therefore, they are under the direction of FTs who work at the general education school. Thus, in these cases, both FTs have a fourth joint area, between the music school and the general education school, which makes the relationship between them even more complex.

Before we present and discuss data, we will approach the concepts of leadership and educational coordination as these are mentioned very often throughout this analysis and are the interpretative basis in this analysis.

This communication is based on the analysis of empirical data obtained from the testimonies of FTs regarding their representations and experiences in leadership and the coordination of teachers among schools in which there is a joint teaching system. The aim of collecting narratives, lead us to reflect on the difficulties and opportunities of the (non)existing intermediate leaderships.
\end{abstract}

Keywords: form tutors, joint teaching system for music, teacher coordination and collaborative work 


\section{INTRODUÇÃO}

Em Portugal, uma das formas de frequentar o ensino da música é através do ensino articulado ${ }^{4}$, sendo que esta é uma componente do sistema educativo do ensino básico ${ }^{5}$, de ordem opcional, que garante a oportunidade de frequentar formação musical e instrumental aos alunos nisso interessados, havendo, para isso, um sistema protocolarizado entre escolas do ensino regular e escolas especializadas de música. Ainda que as escolas do ensino regular, por facilitação organizativa, procurem agrupar os alunos do ensino articulado em turmas próprias, numa mesma turma pode haver alunos nesse regime e alunos não frequentadores do ensino articulado.

O ensino articulado obriga assim a que a escola de Ensino Especializado de Música (EEM) (academias, escolas, conservatórios, privados ou públicos) e a escola do ensino regular se articulem. Para efeitos dessa articulação constitui figura central em ambas as escolas, do ensino regular e do ensino da música, o representante da EEM, aqui designado como DT2. A nossa opção pela designação de DT2 tem a ver com o fato de os alunos que frequentam este sistema se relacionarem também com um DT da escola de ensino regular, o qual será designado por nós como DT1.

A direção de turma, no sistema de ensino português, constitui uma estrutura de gestão pedagógica intermédia, no âmbito do ensino básico, $2^{\circ}$ e $3^{\circ}$ ciclos, e secundário, sendo desenvolvida por um professor designado entre o conjunto de professores de uma turma. Ao DT cabe um cargo de coordenação e orientação educativas com uma tríplice função: orientação educativa dos alunos; relação com os pais/EE dos alunos e coordenação da ação educativa dos restantes professores. Embora a legislação atente para a identificação de perfis adequados na seleção dos professores a serem chamados a exercer este cargo, na prática o mesmo é entregue indiferenciadamente a qualquer professor, independentemente do seu tempo de serviço, da posse ou não de formação especializada ou de outras variáveis.

No caso das turmas do ensino articulado, um representante dos professores de música, com alguma regularidade DTs da escola de

\footnotetext{
${ }^{4} \mathrm{O}$ ensino da música integra três disciplinas: formação musical, classe de conjunto e instrumento. De acordo com o protocolo estabelecido, a frequência destas disciplinas pode ser realizada na escola do ensino regular ou na escola especializada de música. Esta formação, ainda que promovida maioritariamente por uma escola privada, é de frequência gratuita, cabendo ao Ministério da Educação subsidiar o sistema.

${ }^{5} \mathrm{O}$ ensino articulado é ensino público ainda que possa estar protocolado com uma escola de ensino especializado da música privada.
} 
música, passa a fazer parte do conselho de turma sedeado na escola do ensino regular, logo, sob a direção do DT do ensino regular. Assim sendo, nestes casos, à concentração do exercício de inúmeras prerrogativas (cf. Lima, 2011) que cabem a este órgão unipessoal, junta-se ainda a articulação entre DTs como quarta função, já que ambos os DTs têm que assegurar a articulação entre a escola de música e a escola do ensino regular, o que complexifica a ação de ambos. Esta quarta área de articulação procura responder ao que legalmente estava já contemplado na Portaria n. $.^{\circ} 691 / 2009$, de 25 de junho, e que se torna mais claro no enunciado da Portaria $n^{\circ}$ 225/2012, de 30 de julho, para este tipo de ensino: "Os dois estabelecimentos de ensino envolvidos na lecionação dos planos de estudo dos cursos frequentados em regime articulado devem estabelecer os mecanismos necessários para efeitos de articulação pedagógica e de avaliação" (artigo 10, alíne 2).

Na presente comunicação, pretendemos abordar as funções do DT no ensino especializado da música nas seguintes vertentes: orientação educativa dos alunos, relação com os pais/EE, coordenação docente, com principal enfoque na coordenação entre o DT do ensino da música (DT2), o DT (DT1) e os professores do ensino regular. A base empírica do estudo de que aqui se dá conta baseou-se na análise de entrevistas construídas e realizadas com estudantes dos mestrados em ensino, sendo a análise das mesmas da nossa inteira responsabilidade.

\section{ENQUADRAMENTO LEGAL DO DIRETOR DE TURMA NO ENSINO ESPECIALIZADO DA MÚSICA NO ENSINO ARTICULADO}

O ensino articulado da música é uma componente do sistema educativo do ensino básico, de ordem opcional, que garante aos alunos interessados em frequentar formação musical e instrumental, a oportunidade de o fazerem gratuitamente, havendo, para isso, um sistema protocolarizado entre escolas do ensino regular e escolas especializadas de música. Este sistema de ensino foi criado pela Portaria n. ${ }^{\circ}$ 691/2009, de 25 de junho, na sequência dos princípios gerais definidos pela Lei de Bases do Sistema Educativo ${ }^{6}$, nomeadamente no que respeita aos

\footnotetext{
${ }^{6} \mathrm{Na}$ referida lei, para o caso do ensino básico, indica-se como objetivo, no artigo $7^{\circ}$, alínea c): "Proporcionar o desenvolvimento físico e motor, valorizar as atividades manuais e promover a educação artística, de modo a sensibilizar para as diversas formas de expressão estética, detetando e estimulando aptidões nesse domínio", enquanto para o ensino secundário, tem por objetivos; "Assegurar o desenvolvimento do raciocínio, da reflexão e da curiosidade científica e o aprofundamento dos elementos fundamentais de uma cultura humanística, artística, científica e técnica que constituam suporte cognitivo e metodológico apropriado para o eventual
} 
objetivos, prosseguindo também o definido no Decreto-Lei n. ${ }^{\circ} 344 / 90$, de 2 de novembro. O princípio da gestão flexível do currículo está na base deste sistema, potenciando as oportunidades da autonomia das escolas, mediante a qual podem optar, na sua oferta formativa, por Cursos Básicos de Dança, Música ou Canto Gregoriano. O plano de estudos dos alunos que frequentam estes cursos é composto pelo conjunto de disciplinas que integram as áreas disciplinares comuns da educação básica, substituindo as disciplinas de Educação Musical e de Educação Visual e Tecnológica do regime regular pelas disciplinas da área artística, sendo que no Curso Básico de Música, compõem o mesmo a Formação Musical, a Classe de Conjunto e o Instrumento.

As disciplinas da componente artística são lecionadas, obrigatoriamente, por professores especializados de música, de uma escola especializada de música, sendo que os alunos as poderão frequentar, consoante as condições de proximidade ou de decisão organizativa, ora numa ora em duas escolas. Ou seja, estes alunos frequentam o ensino regular numa EB2/3, ainda que possam ter que se deslocar a uma escola de ensino especializado de música para a realização de uma ou das três disciplinas da componente artística.

Ainda que as escolas do ensino regular procurem agrupar os alunos do ensino articulado em turmas próprias, de forma a facilitar a organização de horários, numa mesma turma pode haver alunos nesse regime e alunos não frequentadores do ensino articulado. Os professores das disciplinas de música ministradas, ou um seu representante designado pelo conselho pedagógico da escola de origem, devem participar nos conselhos de turma que se realizam nas escolas de ensino regular, para efeitos de articulação pedagógica e avaliação (ponto 3. Art. . $^{\circ}$, Portaria n. ${ }^{\circ}$ 691/2009). Ainda que na Portaria referida não exista essa atribuição, este professor representante é usualmente designado pelas escolas especializadas de música como DT, coincidindo, em princípio, com o professor de Formação Musical ou de Classe de Conjunto, uma vez que os mesmos trabalham com o grupo total.

Focalizando-nos nos alunos e nos respetivos encarregados de educação, vemos, assim, que os mesmos lidam com dois DTs: um da escola do ensino regular e outro da escola especializada do ensino da música ${ }^{7}$.

prosseguimento de estudos e para a inserção na vida ativa" (artigo $9^{\circ}$, alínea a) e, ainda, "Facultar aos jovens conhecimento necessários à compreensão das manifestações estéticas e culturais e possibilitar o aperfeiçoamento da sua expressão artística" (alínea b).

${ }^{7}$ De referir ainda que há escolas de ensino especializado de música públicas, ou seja, os Conservatórios, que funcionam com base num modelo de ensino integrado (ensino 
Nas escolas particulares ou cooperativas de música, depende dos regulamentos internos específicos a existência ou não da figura de Diretor de Turma, sendo sempre obrigatório, nos casos do ensino articulado, a designação de um professor representante para a articulação com a escola de ensino regular. Assim, este, para além das funções de orientação educativa dos alunos, de coordenação docente e de mediação com os pais/EE, vê acrescida a função de representante dos professores de música no conselho de turma sedeado na escola do ensino regular, logo, sob a direção do DT do ensino regular.

\section{OS DIRETORES DE TURMA E O CONTEXTO ORGANIZACIONAL DAS ESCOLAS DO ENSINO ESPECIALIZADO DA MÚSICA: DIVERSIDADE, REGRAS NÃO FORMAIS E MIMETISMO}

Quando prevista a figura do DT2 nas escolas de EEM, os critérios de atribuição e de seleção dos professores para o seu exercício encontram-se dependentes da direção da escola ${ }^{8}$. Porém, a seleção do professor de formação musical está a assumir-se como um critério comum; indicador dessa situação é o fato de 3 DTs2, das 4 entrevistadas, serem professoras da disciplina mencionada. A opção em causa relaciona-se com a possibilidade de este professor ser docente de toda a turma, o que não aconteceria no caso de professores de instrumento, uma vez que que esses trabalham com um número limitado de alunos.

No que se refere às suas funções, segundo as DTs2 entrevistadas, estas são semelhantes aos dos DTs1, abarcando uma tripla função, como menciona uma DT2:

regular+ensino especializado da música), que se regem pelo mesmo regime organizacional das restantes escolas públicas do ensino básico e secundário, logo, com a identificação clara de apenas um DT.

${ }^{8} \mathrm{Da}$ nossa interpretação, a partir da informação que recolhemos, quer através das entrevistas, quer através de conversas informais com professores do ensino especializado da música, classificamos esta atuação naquilo que Lima designa como regras não formais, na medida em que são regras "produzidas no seio da organização, são regras estruturadas ou semiestruturadas que podem tomar forma escrita e que tanto se podem orientar para a formulação de procedimento operativos das regras formais, como para áreas de intervenção não formalmente regulamentadas ou legalmente consideradas.". E, ainda, "raramente possam estar feridas de ilegalidade" e podem existir "por afirmação de certos objectivos e de certos interesses com expressão na organização, podendo seleccionar bases de legitimação como o profissionalismo, a autonomia em certo tipo de decisões, a pedagogia" (1992, pp.167168). 
o diretor de turma, no meu entender, é acima de tudo um mediador, é o elo de ligação entre encarregados de educação, escola, alunos, professores; é ele o mediador que gere e que está no meio, que tem como responsabilidade a boa relação entre todos, o acompanhamento e a disponibilidade necessária para resolver situações sempre que elas aparecem. (E3).

Admitimos, assim, que as escolas de EEM, por razões que necessitam de ser estudadas, adotam figuras de gestão pedagógica intermédia, e atribuem-lhes funções semelhantes às das escolas do ensino regular, podendo tal situação consistir num fenómeno de mimetismo ou de contaminação (cf. Barroso, 2003) ${ }^{9}$. Também são semelhantes ao caso dos DT1 a atribuição de tarefas administrativas a esta figura de gestão pedagógica, como podemos conferir no discurso de uma DT2, que se segue:

Nós temos que controlar tudo, desde faltas, desde o aproveitamento global dos meninos, desde as faltas. Se um aluno faltou porque faltou e se o pai tem conhecimento (...), tarefas burocráticas, que é verificar documentos, os planos de recuperação, os planos de desenvolvimento, os apoios, todos esses documentos. (E3).

Uma das DT2 entrevistadas refere mesmo ser este tipo de tarefas que lhe ocupa mais tempo no exercício do cargo:

É a organização, talvez a organização do dossiê técnico - pedagógico. (...) porque tem que estar sempre tudo em dia, porque estamos sempre suscetíveis a uma revisão pelo POPH. E nesse dossiê tem de conter tudo o que faz parte da turma, desde planificações trimestrais por disciplina, atas de reuniões, relatórios de atividades, avaliações intercalares, registo de faltas, identificação dos alunos e professores, como as habilitações, bem, uma enormidade de coisas importantes. E em conformidade com isso está a interação com os outros professores da turma, do ensino vocacional, para que isso tudo esteja em ordem dentro dos respetivos prazos, e para organizar isso é preciso perder tempo a organizar isso. (E4).

Pelos testemunhos apresentados regista-se que o peso do trabalho administrativo exigido às DTs2 é desproporcionado; situação muito próxima dos DTs1. Verifica-se, assim, haver uma tensão entre as tarefas administrativas e a componente pedagógica, uma vez que as DTs2 consideram ser na primeira que "é preciso perder muito tempo a organizar

\footnotetext{
9 Barroso (2003) utiliza esta designação para o caso das políticas educativas desenvolvidas em diferentes países; neste exercício exploratório pensamos que a referida designação pode ser aplicada à convergência destas duas organizações educativas: a escola do ensino regular e a escola de música.
} 
isso (documentos vários)" (E4), e que "são alguns documentos que já dão muito trabalho (E3).

Nos pontos que se seguem damos continuidade à apresentação dos dados empíricos, testemunhos de DTs2 de escolas de EEM sobre as suas perspetivas e experiências no ensino articulado da música, mas agora no que se refere às duas vertentes anteriormente mencionadas: a relação com os alunos e a relação com pais/EE dos alunos. Desse modo, a interpretação e a discussão sociológicas das narrativas das DTs2 procuram atentar em alguns dos principais desafios e confrontos que admitimos estarem no centro do exercício da direção de turma nesse contexto específico.

\section{DIRETORES DE TURMA E ORIENTAÇÃO PEDAGÓGICA E EDUCATIVA: INTEGRAÇÃO, ENSINO E CIDADANIA}

Das entrevistas realizadas apuramos que as DTs2 das escolas de EEM desenvolvem, no domínio da relação pedagógica, diferentes funções, desde a integração dos alunos na escola de música, à promoção da aprendizagem, até à educação para a cidadania.

No âmbito da primeira função mencionada, as DTs2 definem-se, no plano do discurso, como a figura privilegiada de integração dos alunos neste contexto organizacional, o da escola de música:

concordo principalmente com a parte da integração dos alunos, porque acho que o DT deve estar sempre em contato com os alunos, deve preocupar-se em saber das suas dúvidas, preocupações, dificuldades, os interesses, e deve acompanhar o desenvolvimento do aluno ao longo do ano. (E4).

A partir destes depoimentos, percebe-se que as DTs2 desenvolvem mecanismos através dos quais recebem os alunos na escola de música, de modo a que estes conheçam e interiorizem as suas regras e, sobretudo, se sintam aí filiados. Para o desenvolvimento da filiação na academia assume especial importância, para uma das DTs2 entrevistadas, o seu papel de incentivadoras do estudo da música:

a atividade mais importante que destaco é a integração dos alunos no meio escolar da academia, motivo-os para a importância do estudo diário do instrumento, bem como sensibilizar os pais para a prática do instrumento e motivação para o estudo em casa. (E1).

Em ambos os discursos apresentados encontramos ingredientes do conceito de integração utilizado por Durkheim (1991), na medida em que as DTs2 mencionam desenvolver uma ação que parece orientada para a criação de uma forte interdependência entre os elementos da escola, bem 
como para a construção de uma consciência comum, voltada para fins comuns.

Nalgumas situações também assume especial importância a ação das DTs2 junto de alunos com dificuldades na aprendizagem do ensino da música, portanto, na promoção do sucesso, em termos de ensino: nós temos tarefas em relação aos alunos que têm, por exemplo, dificuldades; é função do Diretor de Turma verificar se são realizados os planos de recuperação, se os planos de recuperação estão a surtir efeito ou não, dá-los a conhecer ao Encarregado de Educação e monitorizar toda essa atividade. Para além dos planos de recuperação temos os planos individuais de apoio educativo que é para os alunos que têm dificuldades mas não são tão preocupantes, e ainda temos os planos de desenvolvimento que são para aqueles alunos que demonstram especiais aptidões, por isso, isto já são alguns documentos que dão muito trabalho.(E3).

Por essas razões é que uma das DTs2 sinaliza diferenças significativas entre o papel dos DTs2 e os outros professores da escola de música: [o DT2 é importante na] integração e orientação [dos alunos], porque acho que a diferença de um DT e de um professor está relacionada com a responsabilidade que os alunos veem no DT. Eles veem-no como o responsável e como o orientador. Eles confiam (no DT) para o caminho e percurso educativo deles. Eu acho que é essa a diferença de um professor. Porque eles no professor não pensam bem que ele está ali para ajudar, na maior parte das vezes. Para se preocupar com o futuro deles, com aquilo que eles vão aprender. E com o DT eu acho que eles sentem isso. Têm outro... não é respeito, mas têm outra postura perante o DT. (E2).

Uma terceira dimensão sinalizada pelas DTs2 prende-se com a educação para a cidadania, atribuindo-lhe discursivamente grande importância na formação dos alunos:

... como tive de saber os fundamentos do aparecimento da disciplina da Formação Cívica, e se ela fosse lecionada como realmente está na lei, esta disciplina é importantíssima. Não é à toa que existe em todos os países da Europa. Porque no século que vivemos, com a vida atribulada dos pais e famílias, com a falta de raízes e de patriotismo, com a falta ou com o excesso de tudo (nem sei...com a falta ou com o excesso, nem sei bem), a formação cívica é um momento em que os alunos conseguem falar e ter a noção do que deveriam ser, do que é estar em sociedade, o que muitas vezes era dado através da religião. Por exemplo, nos escuteiros, grupo de jovens, aquele tipo ATL [atividades de tempos livres] que havia antigamente. Agora isso não existe (...) poucas crianças participam (nisso). (E3).

Embora a referida área fosse até há bem pouco tempo uma componente do currículo da escola do ensino regular, as DTs2 
consideram que também a exercem na escola de música, não tanto pelo ensino mas mais pela prática, numa espécie de currículo oculto ${ }^{10}$ :

Mas tento fazer com que eles se responsabilizem pelas atitudes que têm uns com os outros e com os professores. (Isto) para crescerem, porque isso faz parte do processo deles. E aquilo da cidadania, o respeito pelos outros, pela educação. Mesmo na escola: (respeito) pelas regras, pelo comportamento. Tento fazer isso. Tento... (E3).

No entanto, eu penso que esta formação cívica e democrática é mantida semana a semana e os alunos são acompanhados para não serem só bons músicos, bons alunos mas serem também pessoas com civismo. (E1).

Para outra DT2, o fato de a lecionação da educação cívica estar atribuída ao DT1, não tem impedido que as DTs2 também se envolvam no seu desenvolvimento, nas suas palavras:

Nós não temos a disciplina de formação cívica, não somos nós que a lecionamos. O feedback que eu tenho, pela experiência (...) pelos conselhos de turma que eu participo dos nossos alunos, há uma ótima relação com os professores do conselho de turma e então o próprio professor de formação cívica procura interagir connosco, com o ensino vocacional. Desde organizar visitas de estudo à Casa da Música, desde falar sobre a postura, sobre a forma como estar em palco, etc., as regras e isso é educação cívica; ou seja, essa parte que faz parte da formação cívica é importante. (E2).

Sem retirar importância a estes contributos, não podemos deixar de mencionar que subjacente a estes discursos encontra-se uma conceção de cidadania ora orientada para os pares, traduzidas em expressões como "respeito pelos outros" (E3), ora para uma dimensão individual de responsabilização na medida em que procuram que os alunos se "responsabilizem pelas atitudes que têm uns com os outros e com os professores" (E3), ora, ainda, por comportamentos de obediência, uma vez que "Mesmo na escola: pelo (respeito) pelas regras, pelo comportamento" (E3). Outros eixos substantivos da educação para cidadania, como, por exemplo, a participação dos estudantes na tomada de decisão sobre a organização e o funcionamento da escola de música, bem como na dinâmica em contexto de ensino da música, não são

\footnotetext{
${ }^{10}$ Santomé (1995, p.201) apresenta a seguinte distinção: “O curriulum explícito ou oficial aparece claramente reflectido nas intenções que, de uma maneira directo, indicam quer as normas legais, os conteúdos a mínimos obrigatórios ou os programas oficiais (...); O curriculum oculto faz referência a todos aqueles conhecimentos, destrezas, atitudes e valores que se adquirem mediante a participação em processos de ensino e aprendizagem e, em geral, em todas as interacções que se dão no dia-a-dia das aulas e escolas. Estas aquisições, no entanto, nunca chegam a explicitar-se como metas educativas a conseguir de uma forma intencional" ( $\mathrm{sic}$ ).
} 
verbalizadas pelas DTs2 entrevistadas, o que pode traduzir a sua não existência, o que, se assim for, põe em causa a criação de oportunidades de os alunos experimentarem o exercício da democracia participativa.

Por outras palavras, o exercício da cidadania no interior da escola de música constitui ainda um desafio (cf. Perrenoud, 2002), sendo, na nossa perspectiva, relevante lembrar que a escola de música tem um papel importante na educação dos seus alunos e, nesse sentido, dificilmente poderá furtar-se a proporcionar experiências de democracia participativa aos seus alunos. Tal como se refere para a escola do ensino regular, organizar uma escola de música "como uma cidade democrática não é um truque de magia, mas exige imaginação sociológica e engenharia social, pedagógica e didáctica para que a sua concretização seja possível, para que a experiência quotidiana seja simultaneamente favorável a uma aprendizagem da cidadania e compatível com as outras tarefas" (ibidem, p.53).

Em jeito de síntese parcial dos discursos apresentados, sinalizamos o conjunto de dimensões que compõe a orientação pedagógica das DTs2, consistindo na integração dos alunos na escola de música, na promoção do seu sucesso no ensino da música e, ainda, no desenvolvimento de práticas que contribuam para o exercício da cidadania por parte dos educandos.

\section{DIRETORES DE TURMA, ENSINO DA MÚSICA E PAIS: DIVERSIDADES E DESIGUALDADES}

As formas como a relação entre DTs e pais/EE se tem desenvolvido são diversas, o que nos obriga a questionar, de acordo com Silva (2003), se, em termos gerais, não estaremos confrontados maioritariamente com uma relação armadilhada; ou seja, será que quando falamos da relação escolas-famílias nos estamos a referir a um diálogo horizontal, há existência de uma verdadeira parceria, em que cada parte, a seu tempo, ouve e faz-se ouvir, ou, em contrapartida, essa relação não estará manietada a partir do interior da escola e dos seus suportes regularizadores, no sentido de que os pais sejam levados a atuar de acordo com as normas preceituadas, sem oportunidade de introduzir novas propostas e dinâmicas na vida escolar dos seus filhos?

A análise aos dados das quatro entrevistas sobre a relação do DT2 com os pais/EE, permite-nos concluir que as entrevistadas consideram que esta é uma dimensão muito importante da sua ação profissional, todas tendo identificado como sua principal função, neste âmbito, a de transmissoras de informação "sobre o desempenho dos seus filhos nas disciplinas do ensino vocacional" (E4). Uma das entrevistadas alarga a 
sua reflexão chamando a atenção para a "obrigação de ter, exatamente, uma boa relação com os pais e perceber que eles são pais, que têm dúvidas, que muitas vezes não percebem as dificuldades que os filhos têm e que os filhos em casa são uma coisa e que aqui podem ser outra..." (E3), no sentido do seu direito a serem respeitados nas suas circunstâncias e ajudados no reconhecimento do acompanhamento dos seus filhos.

Três DTs2 respondentes consideram que a sua relação com os pais/EE se carateriza pela cordialidade, pelo mútuo respeito, na base do reconhecimento pelo fato de as DTs2 estarem "a orientar o percurso escolar dos filhos deles" (E2).

A música, particularmente a clássica, é uma área específica, cujo capital de conhecimento está socialmente distribuído de forma bastante desigual, sendo minoritário o grupo de pais/EE que dominam esse saber. Esta é uma das variáveis caraterizadoras da heterogeneidade do grupo de pais/EE de alunos de uma turma, a que se aliam outras, de ordem cultural diversa. A história do acesso ao ensino da música mostra-nos que as crianças oriundas das classes populares só muito recentemente, em muitos casos a partir da criação do ensino articulado, têm conseguido realizar essa formação. Uma das DTs2 entrevistadas reporta-se à sua experiência em escolas ora do meio urbano, em que o ensino da música tem já alguma tradição, ora de um meio misto em que só muito recentemente abriu uma escola de música, para nos explicitar as diferenças que encontra entre uns e outros pais. Segundo a mesma,

Em VV, a forma como eles nos olham, a forma como eles nos tratam é totalmente diferente. Eles ainda olham um bocado como no tempo do Salazar, em que o professor ainda é uma entidade importante, ainda é alguém que vai ensinar alguma coisa, enquanto aqui na cidade não é assim. Aqui (o professor) é mais um, mais um a querer dar más notas. (E2)

Realçando a diferença de representações existente, alia-se, segundo a mesma DT2, a humildade que "os EE que sejam culturalmente menos habilitados" (E2) manifestam face ao conhecimento musical que sabem possuir os professores.

O saber especializado que os professores de música possuem é identificado pelas DTs2 como um fator de distanciamento e de afirmação científica face aos pais-professores - "na minha direção de turma há alguns PEE's professores mas que não estão por dentro do que é a música e, portanto, respeitam e consideram tudo o que lhes é dito." (E1) garantindo-lhes, assim, um espaço de poder de intervenção forte junto dos pais, respeitando, segundo afirmam de forma consensual, a diversidade cultural existente e adequando a sua atitude relacional a cada um. Ou seja, sabendo nós a heterogeneidade de culturas existente, estando já 
devidamente estudada a proximidade da cultura dos professores com os grupos sociais pertencentes a uma classe média (Silva, 2003), possuidora de habilitações escolares elevadas e, no campo da música clássica, tendencialmente mais atentos, questionam-se as oportunidades das classes populares para a efetividade de uma escolha sustentada em elementos adequados.

Estas DTs2 servem-se de diversas estratégias para conseguirem entrar em comunicação com os pais, seja por telefone, por correio, diretamente ou por caderneta escolar. Realça uma das entrevistadas que "Já escrevi muitos recados na caderneta a dizer que os alunos se estão a portar magnificamente bem e isto é importante." (E3), dando assim, a este instrumento mediador, um uso motivador e estimulante aos pais/EE para o acompanhamento dos filhos.

Revelando representações contraditórias sobre os alunos, ora considerando umas que os mesmos "não são bons mediadores, nem têm obrigação de o ser, porque não têm maturidade" (E3), ou que "alunos que distorcem a informação que lhes é transmitida", (E4), ora considerando outra que "Alguns alunos fazem com que os pais venham à escola" (E2), as DTs2 reportam situações que se enquadram na tipologia do papel das crianças nas práticas de relação família-escola, de Edwards et al. (2000). Segundo estas sociólogas da educação, as crianças podem ser 1) promotoras da relação; 2) promotoras da não relação; 3) passivas face à relação; 4) tão passivas à relação quanto os pais e os professores. $\mathrm{O}$ discurso negativista destas DTs2 sobre os alunos, revelando uma imagem tendencialmente baixa da sua competência e maturidade, enquadra-se sobretudo nos níveis dois e três da referida tipologia. No entanto, não é apontada nenhuma situação enquadrável no nível quatro, já que, para além de manifestarem o seu empenhamento profissional, afirmam também o acompanhamento cuidado que os pais/EE fazem da aprendizagem musical dos seus filhos, sobretudo quando se trata de os mesmos prepararem apresentações públicas em recitais.

A representação que as DTs2 possuem sobre as possibilidades de os pais/EE intervirem, darem sugestões, terem iniciativas face ao processo de aprendizagem na escola dos seus filhos, é bastante frágil: se uma diz que na sua hora de atendimento ouve o que os pais têm para lhe dizer (E1), outra defende que os pais intervêm através dos seus representantes de conselho de turma, transmitindo neste órgão "as informações dos outros encarregados de educação e ouvem as opiniões do conselho de turma em relação à turma e esclarecem" (E3); a terceira (E2) só se refere à pertinência do tratamento individualizado dos casos e a última (E4) confessa não ter reflexão sobre o assunto. 
As DTs2 entrevistadas reconhecem que há, da parte dos pais, uma pressão muito grande sobre os resultados escolares, particularmente nas disciplinas do ensino regular. O ensino da música é entendido por muitos pais, no dizer de E4, como um hobby: "chegam a tirar os instrumentos aos filhos se não melhorarem as notas no ensino regular" (E4). Em contrapartida, a E1 refere que "a preocupação e interesse dos pais foi aumentando gradualmente na escola de ensino regular e na academia". A consciencialização dos pais face ao esforço e pressão que constitui o ensino articulado para os seus filhos (duas escolas, mais disciplinas, mais professores, aumento significativo do tempo de estudo, deslocações acrescidas), leva "os pais a verificarem que eles precisam de acompanhamento e têm também expetativas para que eles possam melhorar cada vez mais". É consensual para estas DTs2 o aumento de competitividade entre alunos e entre pais, enfatizado, nesta área, pelo teor das apresentações públicas dos seus filhos.

\section{5. (IN)EXISTÊNCIA DE LIDERANÇA(S) E DE TRABALHO COLABORATIVO ENTRE PROFESSORES E DTS DE AMBAS AS ESCOLA: CARÁTER PONTUAL, INTERMITENTE E HIERARQUIZAÇÃO CURRICULAR}

Antes de abordar a apresentação e discussão dos dados, importa esclarecer que perspetivamos o DT como figura central na coordenação e promoção do trabalho colaborativo dos professores de uma turma, não limitando a sua ação a uma vertente administrativa-burocrática. A redução da ação do DT a uma gestão burocrática, nas condições atuais, torna-se cada vez mais insuficiente; defende-se, assim, que o seu trabalho assente numa liderança educacional, cujo significado se traduza na "criação de condições e contextos para que os docentes aprendam novas práticas, como comunidade profissional", ou seja, "promover dinâmicas que estimulem a interação e o trabalho conjunto" e, ainda, "apoiar o crescimento de uma equipa e da capacidade de trabalho em conjunto para enfrentar desafios e incrementar os resultados dos estudantes" (Bolívar, 2012, pp.62, 78, 79, respetivamente).

Assim, de entre os vários objetivos subjacentes ao exercício da liderança educacional exercida pelo DT, destacamos o trabalho colaborativo, já anteriormente referido. Neste momento importa mencionar que se trata de

um processo de trabalho articulado e pensado em conjunto, que permite alcançar melhor os resultados visados, com base no enriquecimento trazido pela interacção dinâmica de vários saberes específicos e de vários processos cognitivos em colaboração. Implica conceber estrategicamente a finalidade que orienta as tarefas (de 
ensino) e organizar adequadamente todos os dispositivos dentro do grupo que permitam (1) alcançar com mais sucesso o que se pretende (as aprendizagens pretendidas), (2) activar o mais possível as diferentes potencialidades de todos os participantes (no âmbito do grupo-disciplina, do grupo-turma, ou outros) de modo a envolvê-los e a garantir que a actividade produtiva não se limita a alguns, e ainda (3) ampliar o conhecimento construído por cada um pela introdução de elementos resultantes da interacção com todos os outros (Roldão, 2007, p.29).

Apesar das virtudes potenciais da liderança educacional e do trabalho colaborativo, é necessário reconhecer que ambas apresentam tensões e dilemas (cf. Hargreaves, 1998, Bolivar, 2012 \& Roldão, 2007), particularmente, como no caso em estudo, quando há um conjunto de alunos (turma), que estuda mediante orientações de dois grupos de professores (professores da EEM e professores da EER), e sujeitos, portanto a dois DTs (DT2 - da EEM e DT1 - da EER). Acrescenta-se a este cenário que o ensino articulado envolve professores e DTs pertencentes a diferentes escolas com diferentes culturas, e mesmo diferentes sistemas (público e privado), cada uma delas com padrões particulares de interação entre docentes. Admitimos, assim, que os dois grupos de DTs e professores envolvidos no ensino articulado, não trabalham em isolamento, mas também não trabalham com a maior parte dos docentes da turma (mas antes em subgrupos mais pequenos, tal como o subgrupo do ensino regular e o subgrupo do ensino da música. Assim sendo, não estaremos muito distantes do que Hargreaves (1998, p.240) designa de culturas balcanizadas.

Os DTs2 identificam, sem qualquer dúvida, que no âmbito do trabalho colaborativo, entre todos os docentes dos alunos que frequentam o ensino articulado, "a maior dificuldade é a interacção com os professores do ensino regular" (E4). Quando, eventualmente, alguma articulação existe entre estas duas organizações e seus atores, é resultante da iniciativa da escola e do DT do ensino da música; por exemplo, aquando da manifestação de interesse de participação na festa natalícia organizada pela escola do ensino regular, em que os alunos da música podem dar um contributo significativo. Neste sentido, há DTs2 que são aconselhados "Logo no início do ano pelo Diretor Pedagógico, a manter um contacto permanente com a DT do ensino regular" (E1); outros, por iniciativa própria, desencadeiam esse processo: "na vertente academia/escola regular, fui eu que comecei a dar os passos e por isso eu posso falar porque fui a primeira à ir à escola" (E3).

Para estes DTs2, são também eles quem mais procura articular os dois grupos de atores, pronunciando-se, nesse sentido, dois DTs2, ao 
transmitirem nas suas palavras: "No meu caso, eu tenho a noção que articulo mais" (E1), e "há muito pouca articulação entre a academia e o agrupamento e todas as propostas de actividades foram feitas por mim" (E4). Nalguns casos, chegam mesmo a convidar a DT1 para as reuniões de avaliação na escola de música, embora a adesão a esta iniciativa não seja muito respondida, como refere uma DT2: "por acaso nunca apareceu a nenhuma reunião e aí fazemos a pauta, a qual é enviada para o ensino regular. Normalmente também participo na reunião de avaliação do ensino regular" (E4), ou seja, os recursos burocráticos são instrumentos quase únicos para garantirem alguma ligação entre professores de uma e outra escola. Não obstante as tentativas mencionadas, também há discursos que apontam que "ainda há muito trabalho para fazer" (E6), na medida em que os DTs1 e os professores do ensino regular recebem os DTs2 "um bocadinho de pé atrás" (E3).

Noutras situações verifica-se mesmo a ausência de trabalho colaborativo em cada um dos grupos docentes, sejam da EEM, sejam da escola do ensino regular, por razões várias e multifacetadas. Algumas prendem-se com "constrangimentos administrativos ou de outro tipo que apresentam barreiras ou desencorajam significativamente a possibilidade de procederem de outro modo" (Hargreaves, 1998, p.193). Consideramos que neste tipo de constrangimento enquadra-se a separação física entre as organizações que ministram estas duas componentes do currículo, já que "o facto de não estar lá na escola faz com que as coisas não sejam tão fáceis. “... já tentei falar com a professora de Geografia, e com o Professor de E.V.T. e as coisas não são assim tão ..." (E2). Pode igualmente ser considerado um constrangimento político-administrativo o desaparecimento de áreas do currículo que constituíam um espaço e uma possibilidade para o desenvolvimento do trabalho colaborativo entre DTs1 e DTs2 e respetivos professores, como explica a E3:

porque a área de projecto era a disciplina que mais unia as duas escolas, porque havia projetos em comum com as duas escolas. Há o projeto educativo da escola e na disciplina da área de projeto a gente desenvolvia projetos comuns às duas escolas e que unia os professores, alunos, pais... era fantástico. Tiraram-nos isso este ano e a gente sente muito.

Acresce a estas razões a falta de sensibilização de DTs1 e dos professores da escola regular para o ensino especializado da música, como depreendemos dos discursos desta DT2:

...porque, por vezes, os professores da escola generalista não são suficientemente sensibilizados para a questão do ensino artístico especializado em música e, por vezes, não estão bem por dentro do que se passa e, por vezes, é o DT da academia que tem de explicar, 
que tem de informar que tem de ser solidário e motivar também o DT da escola regular (E1).

Segundo os testemunhos, noutras situações não se trata apenas da falta de sensibilização, mas também do desconhecimento do próprio ensino articulado e das possibilidades formais de colaboração que o mesmo implica, surgindo inclusive situações de tentativas de exclusão desses representantes em arenas de decisão da escola regular, ignorando, dessa forma, qualquer possibilidade de reconhecimento por qualquer tipo de liderança. Na nossa perspetiva, tal situação assume contornos, por parte dos professores do ensino regular, de criação de um cenário promotor de não participação (cf. Lima, 1992) do DT2, enquanto representante da escola do ensino especializado da música, no Conselho de Turma ${ }^{11}$. O testemunho que se segue denuncia justamente essa situação:

os professores do ensino regular nem sabiam direito o que era o articulado, e desde o início do ano que tive problemas ou mesmo bastante problemas na escola do ensino regular. Posso até contar uma passagem muito engraçada: na primeira reunião de avaliação no agrupamento, não me queriam deixar entrar nem fazer parte da reunião, foi preciso chamar o diretor da escola, que trouxe o regulamento e que teve de dizer aos professores que eu fazia parte da reunião, e do conselho de turma (E4).

Transparece daqui uma invisibilidade acentuada de novas oportunidades educativas, que dificulta, logo à partida, qualquer oportunidade de liderança, sobretudo quando a mesma tem que estar previamente assente num trabalho colaborativo entre escola do ensino regular e escola de música. Aqui já não se trata apenas dos constrangimentos administrativos e organizacionais, mas de um outro tipo de constrangimento, este do foro político, designadamente, as representações sociais sobre a desigualdade de estatuto entre a área curricular da música e as demais disciplinas académicas. Relatam os DTs2 que há professores do ensino regular que "durante o ano fazem pressão psicológica com os alunos dizendo que a música era apenas um passatempo, um hobby, e motivam-nos mesmo a desistirem da música" (E4) e que "...há pouca aceitação ainda da música por parte das escolas" (E4). Também a E2 aponta nesse sentido, identificando uma hierarquia entre as disciplinas que compõem o currículo do ensino articulado, a qual se pode traduzir por uma hierarquia entre docentes; segundo esta, há "distinção entre as disciplinas de primeira e de segunda. Isso tem a ver também com a carga horária, que depois faz com que não haja tempo para

\footnotetext{
${ }^{11}$ Sobre o funcionamento do conselho de turma em escolas do ensino regular (cf. Lima, 1986).
} 
grande margem (...)". Esta representação social sobre disciplinas de segunda é acompanhada por uma representação social também da existência de 'professores de segunda', razões que podem ajudar a compreender, logo à partida, que os processos de liderança sejam de imediato coartados. Como pode um professor que não reconhece outro como seu igual em termos profissionais, sentir-se liderado ou respeitar a liderança que este, legitimamente, procura desenvolver?

$\mathrm{O}$ reconhecimento da igualdade de estatuto disciplinar e, por inerência, dos professores respetivos, encontra-se, à partida, desvalorizado pelo "ambiente político-ideológico e em particular as pressões para a prestação de contas [que] condicionam fortemente as escolas no sentido de atenderem, essencialmente, à quantificação dos seus resultados em áreas muito específicas, previamente definidas" (J.A. de Lima, 2008, p.366). Daí que este estatuto menor, atribuído pelos docentes do ensino regular à área da música, deve ser equacionado como pouco abonatório para o trabalho colaborativo entre os atores de ambas as escolas.

\section{CONSIDERAÇÕES FINAIS}

Em termos gerais, na análise que suporta este artigo, realça-se a complexidade da ação das DTs2 pela particularidade de terem que partilhar a direção de turma dos alunos do ensino articulado com a diretora de turma dos mesmos enquanto alunos do ensino regular. Olhando pelo prisma dos alunos, estes têm que atender às regras de cada uma das escolas e à orientação de cada uma das DTs, o que, em termos ideais, implicará uma ação consistentemente articulada entre as duas DTs.

Das narrativas das DTs2 decorre uma absoluta centralidade da sua atenção nos alunos enquanto estudantes de música, referindo-se exclusivamente aos mesmos enquanto alunos do ensino regular no que se refere à distinção de importância que os mesmos e os seus pais/EE atribuem às disciplinas da área da música e da área geral; ou seja, os seus testemunhos indiciam uma sobrevalorização pela preocupação na área musical, a nível da integração dos mesmos na escola de música e na promoção do sucesso educativo nesta componente, e omissão de preocupação pelas outras áreas.

A par disto, é manifesta a sua consciência sobre os contributos que, enquanto DTs2, podem ter para o exercício da cidadania por parte dos educandos. Ainda que a educação para a cidadania esteja associada ao currículo da escola regular, as DTs2 reconhecem esta como uma área de formação transversal, afirmando que a aprendizagem e prática musical, pelas questões culturais que envolvem, bem como pelo tipo de trabalho em grupo e apresentações sociais, constitui um cenário muito adequado 
para a promoção de práticas de cidadania. Porém, um papel mais ativo dos alunos na organização e funcionamento da escola de música e na dinâmica das aulas não é valorizado nos discursos das DTs entrevistadas.

Face à relação com os pais/EE, as DTs2 atribuem-se um papel muito importante, quer como informadoras, quer mesmo como formadoras parentais para o acompanhamento de filhos estudantes de música. A música clássica, a qual constitui a base de formação musical no ensino articulado, é uma área específica, cujo capital de conhecimento, como dizíamos atrás, está socialmente distribuído de forma bastante desigual, sendo minoritário o grupo de pais que dominam esse saber, o que se distingue das disciplinas do corpo comum, já que todos os pais/EE frequentaram o ensino básico, tendo, portanto, referenciais sobre as mesmas. Esta diferença pode ser utilizada pelas DTs2 como instrumento de afirmação e de distanciamento face aos pais ou, como nos diz uma das DT2, ser motivo para justificar a mobilização dos pais/EE no sentido da construção da consciência da importância do incentivo que os mesmos podem dar ao estudo dos seus filhos.

As narrativas das DTs2 evidenciam que distinguem, em geral, dois grupos de pais/EE: um, de meios mais populares, com menor conhecimento musical que, por isso mesmo, valorizam o saber especializado dos professores de música e procuram corresponder ao que lhes é solicitado; outro, integrado em grupos sociais tipificados como classe média, com alguma formação musical, que entendem a importância da formação musical para os seus filhos mas que muitas vezes veem a mesma como um hobby, a considerar de menor importância do que as disciplinas da componente geral. Esta diversidade de situações é entendida pelas DTs2 como um desafio no sentido de conseguirem de todos uma compreensão efetiva da relevância da formação musical e da igualdade de reconhecimento de todas as disciplinas, o que terá repercussões também na valorização dos professores de música como profissionais da educação. A coordenação da ação pedagógica dos professores é outra dimensão analisada neste artigo, realçando-se os dilemas e tensões subjacentes à colaboração e liderança entre DTS. Centrando-nos no DT2 como pivot destas dinâmicas, verificamos que o mesmo recebe uma liderança delegada pela direção da EEM para realizar a coordenação docente dos professores dessa escola, e para articular com o DT1 da EER: em relação aos colegas internos, a coordenação é viável, pela proximidade local, de identidade profissional e por referência a uma cultura organizacional que partilham. Logo, a liderança intermédia que lhe foi atribuída, em circunstâncias comuns, tem todas as condições para ser exercida. Já em relação aos colegas do CT da EER, a situação é diversa: habitam espaços profissionais distintos, não partilham da mesma 
identidade cultural e profissional, e movimentam-se em espaços, quando aí se deslocam para as reuniões de CT, em que são estatutariamente desconhecidos pela maioria dos membros da EER; logo, falar em liderança, neste caso, é um logro; quando muito, poderá haver acordes de articulação entre os DTs, e não um trabalho desenvolvido com a maior parte dos professores do conselho de uma turma (enquanto um todo). Neste contexto, a coordenação do DT2 sobre os professores de DT1 é inexistente, e qualquer trabalho colaborativo entre docentes de uma e outra escola pode ser seriamente constrangido. A situação descrita assume traços das culturas balcanizadas, tratando-se mais de uma colaboração que divide os dois grupos de professores e DTs (cf. Hargreaves, 1998), uma vez que, a concretizar-se, volta-se apenas para o interior de cada um dos grupos. Assim, reconhecendo a complexidade da vida académica dos alunos do ensino articulado, a dissonância existente entre cada um dos seus DTs pode influir seriamente em todo o seu processo de aprendizagem. Ainda noutro patamar, não foi revelada em nenhuma narrativa, o reconhecimento sobre o papel de coordenação dos DTs1 em relação aos docentes das EEM e, para além disso, não cabe a qualquer direção de alguma das escolas ter algum papel na indicação dos DTs que irão estar em contato com a outra.

Confrontando com Bolívar quando defende a existência de uma liderança educacional, cujo significado se traduza na "criação de condições e contextos para que os docentes aprendam novas práticas, como comunidade profissional", ou seja, "promover dinâmicas que estimulem a interacção e o trabalho conjunto", verificamos, pela análise feita, que há ainda longos percursos a percorrer para que, de fato, se efetive uma liderança partilhada entre DTs2 e DTs1 de forma a "apoiar o crescimento de uma equipa e da capacidade de trabalho em conjunto para enfrentar desafios e incrementar os resultados dos estudantes" (Bolívar, 2012, pp. 62, 78, 79, respetivamente).

Para concluir, importa referir que a análise desenvolvida é tida por nós como parcial, na medida em que a mesma deve, no futuro, ser confrontada com as representações e experiências dos DTs da EER que participam especificamente no ensino articulado da música.

Enquanto investigação em processo sobre o binómio direção de turma e ensino articulado, este estudo prosseguirá o seu aprofundamento e alargamento às representações dos diferentes atores (DTs1, alunos, professores de umas e outras escolas) envolvidos nesta complexidade organizacional, tendo como foco de referência o aluno do ensino articulado de música. 


\section{REFERÊNCIAS}

Antunes, Fátima; GOMES, Carlos; MARTINS, Fernanda \& SARMENTO, Teresa (2012), "Construir a relação pedagógica em tempos de incerteza: perspetivas e experiências de direção de turma. Atas ao III Congresso ibero-americano de política e administração da educação", Gestão pedagógica e política educacional: desafios para a melhoria da formação e profissionalização dos educadores, Zaragoça: Forum Europeu de Administradores de la Educación del Estado Espanhol, Associação Nacional de Política e Administração da Educação e Forum Português de Administração Educacional, 203-214.).

Bolívar, António (2012), Melhorar os Processos e os Resultados Educativos, Vila Nova de Gaia: Fundação Manuel Leão.

Barroso, João (2003). A Escola Pública: Regulação, Desregulação e Privatização, Porto: Edições Asa.

Durkheim, Émile (1995). O Suicídio: Estudo Sociológico, Lisboa: Editorial Presença.

Edwards, Rosalind et al (2000), "A typology of parental involvement in education centring on children and young people: negotiating familialisation, institutionalisation and individualisation", in British Journal of Education, 21, nº3, pp. 435-455.

Hargreaves, Andy (1998), Os Professores em Tempos de Mudança, Lisboa: Mc Graw Hill.

Lima, Jorge Ávila (2008), Em Busca da Boa Escola: Instituições eficazes e sucesso educativo, Vila Nova de Gaia: Fundação Manuel Leão.

Lima, Licínio. (2011), Administração Escolar: Estudos, Porto: Porto Editora.

Lima, Licínio (1992), A Escola como Organização e a Participação na Organização Escolar, Braga: Instituto de Educação e Psicologia, Universidade do Minho.

Lima, Licínio (1986), O conselho de turma: um exercício de simulação, Braga: Área de Análise Social e Organizacional da Educação da Universidade do Minho.

Perrenoud, Philippe (2002), A escola e a aprendizagem da democracia, Porto: Edições Asa.

Roldão, Maria do Céu (2007), "Questões e razões. Colaborar é preciso: questões de qualidade e eficácia no trabalho dos professores", Noesis, 71, 24-29.

Santomé, Jurjo (1995), O curriculum Oculto, Porto: Porto Editora.

Silva, Pedro (2003), Escola-Família, Uma Relação Armadilhada Interculturalidade e Relações de Poder, Porto: Edições Afrontamento. 


\section{Leis e Portarias}

Decreto-Lei n. ${ }^{\circ}$ 344/90, de 2 de novembro - Estabelece as bases gerais da organização da educação artística pré-escolar, escolar e extra escola.

Lei n. ${ }^{\circ}$ 46/86, de 14 de Outubro - Lei de Bases do Sistema Educativo. 1986.

Portaria n. ${ }^{\circ}$ 691/2009, de 25 de junho - Criação dos Cursos Básicos de Dança, de Música e de Canto Gregoriano.

Portaria n. ${ }^{\circ}$ 225/2012, de 30 de julho. - Regulamentação do ensino articulado da Música. 